\title{
THE DIAPAUSE PORTION OF THE LARVAL PERIOD OF DIAPREPES ABBREVIATUS L.
}

\author{
By George N. WolcotT, Entomologist, \\ Insular Experiment Station, Río Piedras, Puerto Rico
}

Investigations on the life-history of Diaprepes abbreviotus L., initiated more than three years ago, are at present sufficiently complete to justify another report of progress. In a previous paper (1), the first part of the larval period, that of growth, has been discussed. Results of the rearings of the past year, conducted with grubs hatching from egg-clusters collected in alternate months throughout the year, indicate that little is to be added to the data there given on this part of the larval period. The variation in rapidity of growth is apparently not, to any considerate extent, due to time of year, but to the individuality of grubs, and the variation in vigor of grubs from different egg-clusters.

To eliminate possible disturbing factors in the more recent experiments, all egg-clusters were collected from a single small citrus nursery on the Station grounds at Río Piedras. At the beginning of the experiments, a single large can of soil was collected, and from this all soil used in the rearing work was taken as needed. Only rain water was used for moistening the soil. The grubs were supplied only with corn for food. All of the cans containing the growing grubs were kept in the same desk drawer, and, so far as possible, received the same treatment. The soil in the cans was maintained at a uniform humidity, so that ordinarily a single medicine-dropperfull of water at two-day intervals restored it to optimum humidity. The cans were examined three times a week; partly eaten corn and too large seedlings removed, growth of the grubs observed and recorded, fresh food and water added, and each can promptly returned to its place in the drawer beside the others. No record was kept of temperatures, but they were substantially the same as those recorded for the Station in the official Weather Bureau kiosk a few hundred feet distant.

One grub, from an egg-cluster hatching September 7, 1933, molted to eighth instar (which is considered the equivalent of having attained full growth) in 48 days, and two other individuals from this same exceptionally vigorous egg-cluster molted to eighth instar in 53 and 58 days, respectively. The best record for rapid growth 
previously obtained was 59 days. Actually, this means little, for other individuals from the same cluster, receiving exactly the same treatment and having exactly the same opportunity to obtain food, required 100 and 119 days to attain the same size. The average period required by the 26 grubs reared from this cluster was 72 days; that of another cluster hatching in September 78 days. That of grubs from three clusters hatching in July was 86 days; that of grubs from three clusters hatching in November 85 days; of one cluster hatching in January 98 days, of another cluster hatching in January, the minimum was 100 days; of one cluster hatching in March, the minimum was 110 days. (Records for other months not yet available.) These records would appear to indicate that season of the year may have some effect, but temperatures certainly have little to do with rapidity of growth.

Admittedly, these records are obtained when the grubs are kept under what are supposed to be optimum conditions of food, cleanliness and moisture, and possibly they give little indication of what might be normal conditions in the field, especially in the more arid regions. The soundness of this criticism rests on the assumption that Diaprepes grubs ordinarily occur abundantly in arid or semi-arid regions; actually they are numerous mostly in irrigated fields where the soil is artificially maintained at a more or less even humidity by irrigation. In any case, the records establish a basis from which to estimate the effect of less favorable environments. That the conditions were optimum for growth is indicated by the fact that mortality among the growing grubs was practically nil, after each, in the 3rd or 4th instar, had been placed in a separate can. In the earlier instars, all the grubs from one egg-cluster were kept in one can, and the mortality due to crowding was high. Presumably, such mortality does not occur in the field, where the grubs disperse widely, and do not come in contact with each other after entering the soil. Even in the cans, crowding may not have been the only factor involved, for many more grubs survived to be transferred to separate cans out of what are designated as the more vigorous egg-clusters. No indication of vigor was to be noted in the egg-cluster itself, but the grubs from such clusters molted to second instar in a half or even a third of the time required by the grubs from other clusters. This appearance of superior vigor may be a delusion, and may have been induced entirely by a more favorable environment. Yet every effort was made to provide equally favorable environment for each egg-cluster: sprouted corn seedlings with some tender roots, in soil not quite so moist as that maintained 


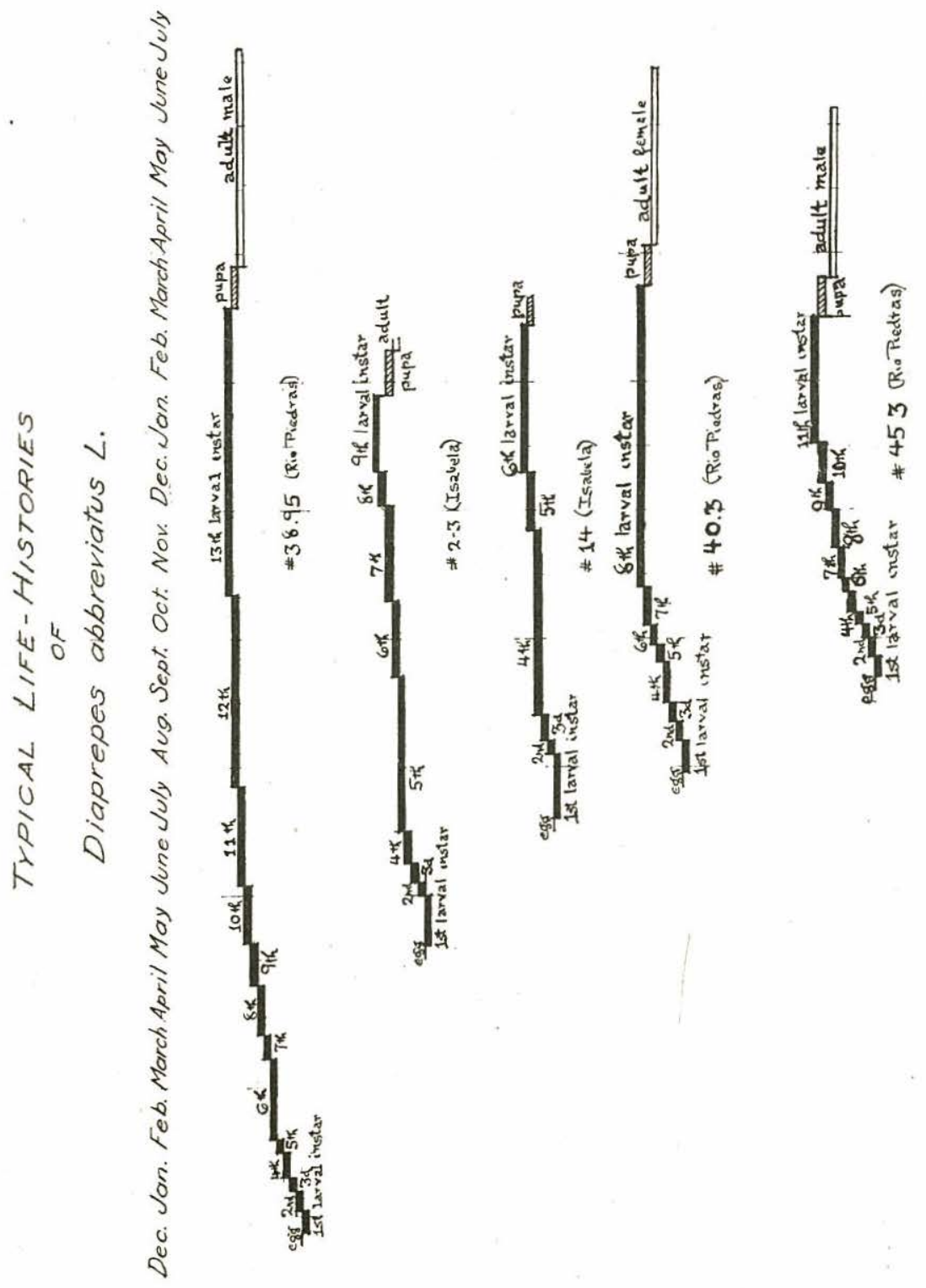


for the older grubs. It seems hardly likely that such slight differences in environment as would not be obvious to the experienced technician would so profoundly modify the vigor of the grubs as to be apparent not only in the number surviving and the rapidity of growth in the earlier instars, but still obvious thruout the growing period.

The success in rearing the grubs in the earlier growth instars was not, until recently, equaled in that of the later period of waiting previous to pupation. Out of all the grubs reared in 1932-33, only one survived to pupate. No assignable cause for death was apparent, yet each successive examination disclosed one or more deaths. Some of the grubs gave the appearance of being partially roasted, and to reduce the temperatures to what might be normal in the field, all the cans were placed in a cellar under the library building. The maximum and minimum thermometer kept beside them indicated little difference in temperatures from those obtained in the standard Weather Bureau kiosk outside, and fatalities continued, so that by fall only one grub was alive. Obviously, some other type of container must be provided to enable the grubs to live thru this waiting period before pupation.

One possible method of reducing temperatures, comparable to what occurs in the field, would be to have the container open at the top, inducing evaporation of moisture from the exposed soil. If an abundance of moisture were supplied from below at short intervals, the difference in temperature might mean the difference between the death of the grub and its successful pupation. To obtain such a container, thick glass tubes, an inch in diameter by four inches long, open at both top and bottom, were used. The bottom was closed by means of a plaster of Paris plug, $3 / 4$ to $1 \frac{1}{2}$ inch in height, poured into the tube, and such tubes, with a porous bottom, were placed on moist sand. Two-thirds full of soil, they promised to offer a superior environment for the grubs. To better understand the later modifications that were found necessary in the equipment of these tubes, a fuller discussion of the activities of the grubs during this waiting period should be given.

Molting to eighth instar has arbitrarily been taken as marking the transition from the period of growth to that of waiting before pupation, as most grubs attain their maximum weight at this time. At best, however, it indicated only the average of all grubs, not the condition of any individual grub. One precocious grub (No. 14 Isabela), as recorded in the previous paper, pupated from the sixth instar, and did most of its waiting when only half grown, in the 
fourth instar. (See life-history chart, Fig. 3). This was during the months of September thru November, so this period ean hardly be either aestivation or hibernation. Possibly it might be called a "diapause," a general term for such periods of waiting until the proper stimulus is received for a continuation of growth or transformation to the next stage of development. In the case of the grubs of Diaprepes, Dr. W. Dwight Pierce advises that it might more specifically be called "delayed pupation, active diapause." Ordinarily, it occurs when the grub has attained full size. During the first part of the period, the grub is exceptionally active or restless. In the closed containers, the earth is so thoroughly churned up that the corn seeedlings come to the top with most of their roots broken off. Later, especially if the soil is exceptionally moist, the grub may form an oval chamber in which it rests quietly, or this may be extended for several inches, and possibly in nature might be quite extensive. The grub rests in the chamber, but is roused to immediate activity when disturbed, and there is nothing suggestive of dormancy in the fact that it has made a definite chamber in the soil.

The beginning of this active diapause is evidenced by the fact that the grub ceases to eat. It may nibble a bit at the corn seedlings, but usually such injuries as they sustain are caused by the restlessness of the grub, rather than by its feeding. Its tentative nibbling is in no way comparable to its voracity of a few weeks previous, when it was making most rapid gains, and often almost entirely devouring one or two, or even three, grains of corn within two days. Ordinarily, the grubs which have grown most rapidly molt to ninth or tenth, or even eleventh instar before ceasing to eat, while those which have been most leisurely in attaining full size often show signs of having attained full growth by the time they have molted to seventh instar. In general, the grubs of an egg-cluster reach full size at about the same time, or at least this is a sufficiently close approximation to the fact so that all can be treated alike at the same time. When all the grubs gave plain indications that they were no longer eating, they were transferred to the open tubes. This was in from 100 to 125 days after hatching.

The first grubs transferred were still in the stage of aimless restlessness, when they were never quiet for long. Some of these grubs apparently came to the surface of the soil, something that would rarely occur in nature, but was induced by their cramped quarters in the tube, and as they were not found later, were presumably devoured by the lizards which infested the insectary. Others not only burrowed thru the soil, but also into the plaster of Paris stopper, 
thru it, and escaped into the moist sand beneath. These could berecovered, and replaced in their tube, or a fresh one, but often repeated their escape from its confined area. To confine them within the tube, fresh tubes were prepared with a round section of wire screening sunk into the stopper by pouring an additional small amount of plaster of Paris on top of the screen. Such looked well

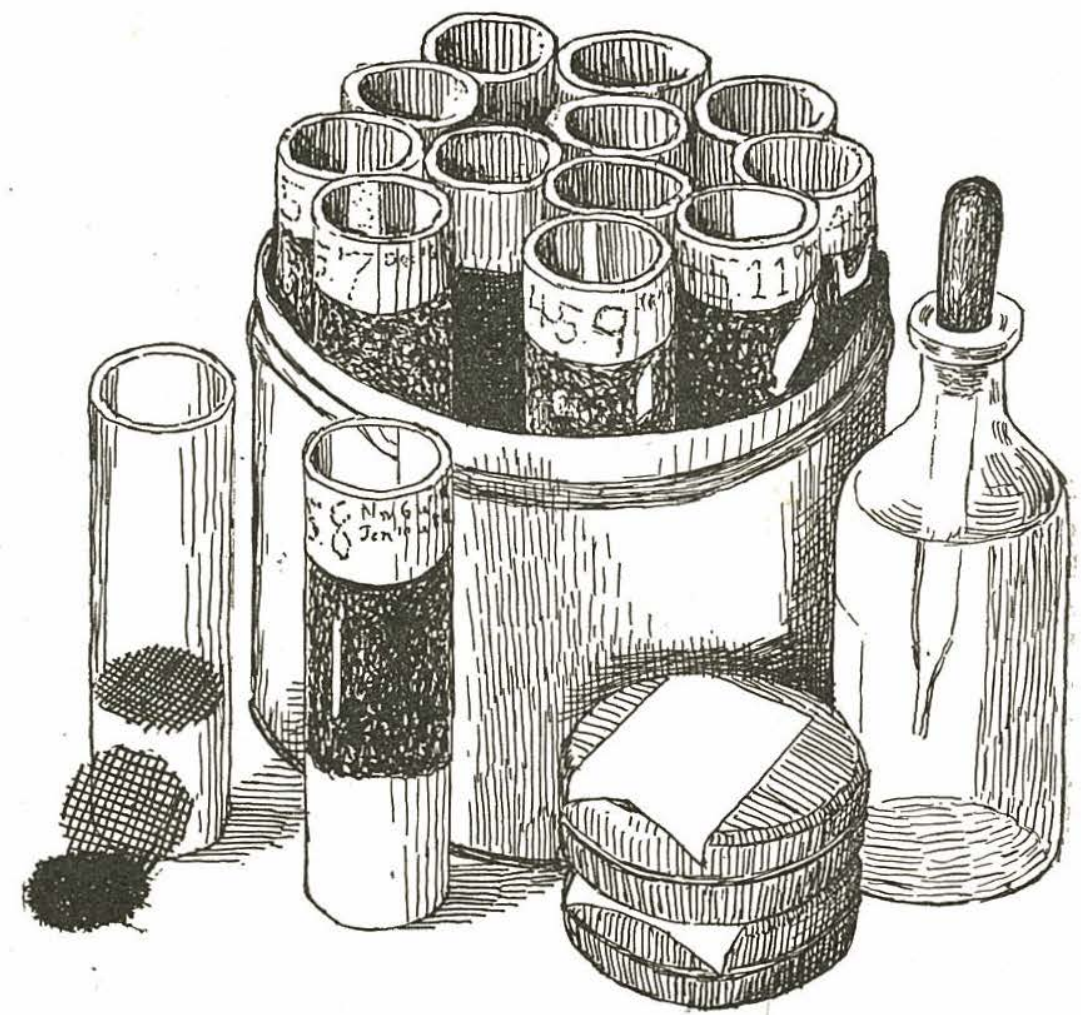

Fig. 4. Equipment used in rearing Iarvae of Diaprepes abbreviatus I. (Original).

before being used, but the restless grubs churned up so much of the plaster of Paris above the screen that later practise consisted of placing earth directly on the screen. (In the accompanying drawing, the completed tube, before adding the grub or earth is at the left; in front of which is a small pile of the circular screens, with one erect on top. Next is a tube in use, with earth, grub and label; behind is a series of tubes containing grubs from one egg-cluster, placed together on moist sand. In front are the tin salve boxes used for rearing during the growth period, and to the right the bottle of rain 
water with medicine-dropper used for maintaining constant humidity in the cans.) One later refinement was to place another bit of screen on top of the earth, somewhat retarding evaporation to be sure, but at least insuring the safety of the grubs from the omnipresent powling lizards.

Previously unused portions of earth were placed with the grub in the tube, and as this earth had been air-dry for six or eight months previously, trouble was avoided from mites, worms and other soil inhabitants that had often become numerous in the closed containers and may possibly have been contributing factors in causing the death of the grubs. The grubs were not supplied with food in the open containers. It was anticipated that the small bore of the tube would give the grubs so little room that they could be kept under . constant observation. Actually, the grubs were remarkably successful in keeping hidden most of the time, and for thoro inspection, most of the earth had to be dug out of the tube until the grub was exposed. Naturally, this could not be done often, and in practise, the tubes were casually examined only once or twice a week to add additional water to the sand beneath them. Rain water was added until the sand was saturated, and sometimes if the tubes seemed dry just above the plug, water was also added from above. Actually, the soil at the bottom of the tubes was found to be always very moist, when removed, even tho the top might be a hard, dry crust.

The first indication of the success of the use of this open-top type of container in permitting the grubs to pass this period of waiting previous to pupation was given on March 1, 1934. On this date, a clear area at the side of a tube containing a grub which had hatched from the egg on September 11, 1933, was noted, which, on being more closely examined was found to be a window thru which a freshly formed pupa could be plainly seen. The window was higher than it was wide, indicating that the pupal chamber was vertical, rather than horizontal, as had been all the chambers previously made by grubs in earlier stages of their existence. The pupa was entirely milky, waxy white, and very active when the tube was picked up. Such activity is presumably normal, for in this case it had caused the window by scraping away the mud separating the chamber from the glass, and apparently serves to further enlarge the chamber after pupation and to compact its sides. The pupa rested on its anus, vigorously wiggling from side to side, and gradually revolving on this as an axis. Within a few days its eyes had darkened, somewhat obscuring the individual facets which were at first very distinct, 
its claws were black and the underwings also being somewhat darker than the remainder of the pupa. When observed on March 19th, it had transformed to a soft adult.

Within a few days, similar windows were observed in other tubes, and later, all tubes were opened, to find that in most cases the grubs had formed vertical pupal chambers in their base, but equidistant from the sides so that no external indication of the chamber was visible.

Of the twenty grubs which had hatched from eggs laid in July, one had died sometime early in April, after having molted to the ninth instar after 109 days, and to the tenth instar after 248 days, on March 26th. Another died in May, from undetermined cause. Six had disappeared, presumably having been eaten by lizards, hardiy a normal end for soil-inhabiting grubs, and presumably practically never occurring in nature. All the others, 12 in number, pupated some time during March, and had transformed to adult after the middle of the month or early in April.

Of the 36 larvae which had hatched from eggs laid in September, 12 pupated in March or early in April, and transformed to adult shortly afterwards. (In all observed cases, the pupal period was not more than a day or two longer or shorter than 15 days, and this may be considered normal, as is 7 days for the eggs to hatch after deposition: surprisingly definite and fixed by comparison with the elasticity of the larval period.) Of these, two had reached eighth instar in 48 and 53 days respectively, and two had required 100 and 119 days to attain full size. That is : the two grubs which grew most rapidly and the two (out of the same egg-cluster) which grew most slowly, all pupated, and shortly afterwards became adult, at practically the same time. Of the others from these clusters, 8 died or disappeared during the spring, 2 pupated in May, 5 in June, 3 in July, 2 in August, while 4 are still active larvae at the end of August.

The grub with the shortest larval period was the one first noted, which, hatching on September 11th, molted to the eleventh instar after 115 days, and was first noted as pupa after 170 days, on March 1st. It had transformed to an adult by March 19th, after 188 days. To be sure, this adult was not hard enough to emerge from the ground, but it indicates a possible rapidity of development from egg to adult of only a little more than half a year. If the progeny from this individual could develop even a little more rapidly, this would seem to indicate the possibility of two generations in a year. Actually, all data point to no such possibility, for it did not come to the surface 
of the soil until April 28th, and proved to be a male. Females do not begin oviposition until several days after emerging from the ground, seven days are required for hatehing, and all grubs hatching from eggs laid in the spring grow slowly and have a longer diapause period than those hatching in the summer or early fall.

As an indication of what may be expected of grubs hatching later in the year, the case of the single grub which survived from the previous year's rearing may be cited. Hatching December 24, 1932, it grew more slowly than others from this exceptionally vigorous egg-cluster from Florida, Puerto Rico, molting to the eighth instar after 91 days, and after increasingly greater intervals to the thirteenth instar after 303 days, and was one of the first grubs to be placed in an open tube, in November 1933. Its development can not be detailed thereafter, for it not only avoided the side of the tube, but when the earth was later removed, it was found that the grub had burrowed into the center of the plaster of Paris stopper so that it was completely hidden from sight. Apparently, however, it had found a suitable environment, for when the stopper was broken up on March 23, 1934, a fully formed and quite hard male adult was found. Returned to the pupal chamber, it remained alive there quietly resting until April 28th. As an aerial adult it lived until. July 5th. This individual had required somewhat less than 452 days from egg to adult, which presumably is the normal complement to other individuals which completed their transformation in much less than a year. Its total life was 557 days, or slightly over 11/2 year. None of the fully grown grubs which hatehed from eggs laid in November, 1933, show any indication of pupation in the spring or summer of 1934, altho all have attained their complete larval growth. Interpolating with the data of the three other grubs that have been reared to pupa (reported in the previous paper), it appears that the normal life-cycle of Diaprepes abbreviatus is completed in a year. Adults are most abundant in the late spring and early summer, and from the eggs laid by the females at this time, grubs develop during the fall which have their resting period during the winter, pupate in March of the following spring, and emerge as adults ready to complete the cycle just a year later. This is the normal cycle.

Practically all of the grubs hatching during July and August are able to complete their development by next spring, most of those hatching in September are able to do so. Possibly a few or those hatching in October are able to complete their life-cycle within half a year, but these are the exceptions, and all those hatching during later months have the extremely long life-cycle that is completed in 
the second spring following. Some grubs may pupate at times other than in the spring, but the evidence to date consists of:

1 pupa in late January (shortly before Jan. 27th).

1 pupa in February.

22 pupae in March.

2 pupae in April.

2 pupae in May.

5 pupae in June.

3 pupae in July.

2 pupae in August.

1 pupa in September.

Transformation to adult, in the case of insects with subterranean immature stages, does not necessarily mean immediate emergence of the adult and its prompt functioning to start a new life-cycle. A great diversity of habits is to be expected of Diaprepes, and presumably some of the adults do not emerge from the ground when most of the others do, but appearing first much later, survive to lay eggs in the fall and winter. Of fourteen adults on which observations are available, one emerged from the ground only twenty days after transformation from the pupal stage; most of them remained in the ground for a month or a month and a half; one for over three months. Adults are most abundant in the late spring; and cause the maximum of damage then by feeding on the tender leaves of citrus and avocado seedlings. Even in captivity, some adults after emergence from the soil live for two and three months, and doubtless some of them live even longer in nature. These possibilities of variation in adult behavior may explain the presence of egg-clusters in every month of the year, but regardless of how one may account for their presence, the writer has experienced no difficulty in obtaining an abundance of eggs during every month of the year, at Río Piedras. They are ever so much more abundant, however, during the late spring, and this should fit in with the normal life-cycle of a year.

Apparently the most important factor in causing the variation found in the habits of Diaprepes is the presence of the egg-parasite, Tetrastichus haitiensis Gahan. This parasite is so abundant in the late spring and early summer that 95 per cent of parasitism of Diaprepes egg-cluters has repeatedly been observed at this time, when the host eggs are most numerous. As the season advances, the percentage of parasitism drops rapidly, and during the winter and spring is so low that only rarely are parasitized elusters found. Thus the parasite is of great value in reducing the numbers of grubs at the 
time when they would normally be most abundant, but has little effect on them at other seasons of the year when they are relatively scarce. This naturally results in the survival of the progeny of exceptional adults, late to emerge from the ground or exceptionally long-lived and slow in oviposition, which escape parasitizm in the egg-stage. It would appear that the presence of the parasite is largely resonsible for disturbing the normal life-cycle of Diaprepes, for many of the adults appearing each spring are from egg-clusters laid out-of-season, which have thus escaped destruction by Tetrastichus.

This would also explain the more pronounced seasonal abundance of Diaprepes where all the land is planted to cane, for under these conditions, the eggs are laid between cane leaves, the tough tissues of which effectually prevent their being parasitized by Tetrastichus. This has two practical applications. (1) The period of hand-collection in cane regions may well be concentrated in the months of abundance. (2) To protect young citrus nurseries from grub attack, however, collections must be continued thruout the year, for the few beetles present in the fall, winter and early spring will lay as many eggs which will develop into grubs as do the great number of beetles appearing in the late spring. The flush of beetles in the spring causes the greatest damage to the leaves of the seedlings, but to protect their roots from damage by grubs, hand-collection of adults at ALL seasons of the year is indicated as being essential.

\section{SUMMARY}

By using an open-top, porous bottomed type of individual container for grubs of Diaprepes abbreviatus L. during their resting or "active diapause" period previous to pupation, numerous individuals have been successfully reared to adult.

In most cases observed, pupation occurs in the spring, regardless of when the grub hatched.

Few of the many egg-clusters laid in the late spring produce grubs, because of heavy parasitization by Tetrastichus haitiensis Gahan, but during the remainder of the year this parasite is searce.

Diaprepes egg-clusters have been found in every month of the year; the grubs from some of these pupating in the next spring and completing their development in little more than six months, others have an exceptionally long "active diapause" terminated by pupation in the second spring, resulting in a life-cycle of several months more than one year. 
428 THE JOURNAL OF AGRICULTURE OF THE UNIVERSITY OF P. R.

\section{BIBLIOGRAPHY}

1. Wolcott, G. N. "The Larval Period of Diaprepes abbreviatus L.' The Journal Dept. Agr. Puerto Rico, 17 (3): 257-264, pl. 1. San Juan, July, 1933. 